\title{
O PROINFANTIL E O CICLO DE POLÍTICAS NO MUNICÍPIO DO RIO DE
}

\section{JANEIRO}

\author{
Maria Ignez Ferreira Campos ${ }^{1}$ \\ Vera Maria Ramos de Vasconcellos ${ }^{2}$
}

\section{RESUMO}

O presente trabalho é parte da pesquisa de mestrado intitulada "O PROINFANTIL no município do Rio de Janeiro: concepções de criança nos Projetos de Estudos". A pesquisa teve por objetivo analisar a implantação da política pública de formação dos profissionais de Educação Infantil, no município do Rio de Janeiro - PROINFANTIL - Programa de Formação Inicial para Professores em Exercício na Educação Infantil. Procurou-se compreender as (re)significações dos conceitos de criança tão relevantes para a atuação profissional de 44 Agentes Auxiliares de Creches, após a participação deles no curso de formação. A abordagem teórica escolhida foi o ciclo de políticas policycycle approach (BOWE; BALL; GOLD, 1992; BALL, 1994), que propõe uma análise das políticas num processo histórico, dialógico e plural. Neste artigo o ciclo de políticas é compreendido a partir de três contextos básicos: (i) de influência, (ii) da produção do texto da política e (iii) da prática. Cada um dos contextos apresenta arenas de discussão, disputas e grupos de interesses por isso, envolvem embates. Foi analisado o PROINFANTIL e as tensões das demandas legais, elementos do contexto de influência e suas disputas sobre as finalidades e os meios utilizados para a construção do programa, enquanto política pública, sob a ótica da legislação vigente à época da sua confecção. $O$ programa de formação, enquanto elementos do contexto da produção do texto da política - analisando a proposta do curso em questão, sua incorporação e intervenções textuais com as limitações materiais e possibilidades vivenciadas 1Doutoranda do ProPEd/UERJ, Brasil. mariaignez66@gmail.com

2Professora Titular do ProPEd/UERJ, Brasil. vasconcellos.vera@gmail.com

Criar Educação, Criciúma, v. 6, n², julho/novembro 2017.-- PPGE - UNESC 
no contexto da prática, referentes às transformações das concepções de criança apresentadas pelos 44 cursistas em seus trabalhos finais (Projetos de Estudo) e a influência do programa de formação, além de suas próprias vivências enquanto profissionais de Educação infantil. Este produto final de curso foi entendido dentro de uma conjuntura maior: por um lado, o próprio curso de formação - PROINFANTIL - com seu material didático e suas aulas; por outro, o fazer cotidiano na creche na qual a AAC trabalhava, o suporte institucional às suas práticas e, por último, a Secretaria Municipal de Educação à qual as creches e as próprias AAC estavam vinculadas. Além disso, teve por objetivo captar, nos Projetos de Estudos, as representações de criança de uma pedagogia para a infância carioca, mediada por um fazer pedagógico que se encontrava imerso no espaço-tempo das práticas sociais realizadas pelas AAC.

Palavras-Chave: PROINFANTIL, Formação de Professores, Ciclo de Políticas.

\section{ABSTRACT}

This work is part of a Master thesis entitled " PROINFANTIL in the municipality of Rio de Janeiro: the conceptions of the Child in the project of studies". The research aimed to analyze the implementation of public policy formation of the professional in the area of Early Childhood Education - PROINFANTIL -(Initial Training Program for Teachers in Exercise of Early Childhood Education. It sought to understand the signification and resignification of the child as a relevant concept for the professional performance of 44 Nursery Auxiliary Agents (NAA). The chosen theoretical approach was the policy cycle approach (BOWE; BALL, GOLD, 1992; Ball, 1994), which proposes a political analysis in a historical, dialogical and plural process. In this article the policy cycle is understood from three basic contexts: (i) influence, (ii) policy text production and (iii) practice. The text analyzes PROINFANTIL and the pressures of legal demands. The training program examined the proposal of the course in question. The final course product was analyzed in a larger context. On one hand, the training course - PROINFANTIL - with its educational materials and its classes; on the other hand, the daily tasks at the nursery where the NAA work, 
the institutional support to their practices and the City Department of Education . The research aimed to capture- in the studies project- the representations of child of in Rio de Janeiro mediated by pedagogy experiments and social practices performed by the NAA.

Keywords: PROINFANTIL, Teacher Training, Policy Cycle

\section{INTRODUÇÃO}

O artigo discute como se deu o PROINFANTIL na cidade do Rio de Janeiro e o analisa a partir da abordagem do ciclo de políticas formulada por Stephen Ball e colaboradores (1992, 1994, 2006, 2011). O PROINFANTIL foi um curso de formação de professores ministrado em todo território nacional, entre os anos de 2006 e 2011 em parceria com Estados e municípios. O programa foi formulado em 2004, inspirado em outro de formação de magistério (Proformação ${ }^{3}$ ), que lhe serviu de referência na formulação da metodologia e identificação das parcerias entre as três esferas administrativas da federação. O programa tinha a finalidade de agilizar a Lei de Diretrizes e Bases da Educação Nacional (LDBEN 9.394/96, artigo 62) ${ }^{4}$, que embora priorizasse a formação em nível superior para o exercício do magistério na Educação Infantil e nas quatro primeiras séries do ensino fundamental, admite a formação em nível médio: modalidade normal. Na cidade do Rio de Janeiro foi desenvolvido no biênio 2010-2011 e objetivou qualificar profissionais em exercício na Educação Infantil sem habilitação, no caso: os Agentes Auxiliares de Creche $(A A C)^{5}$. Era um curso semipresencial, planejado em caráter 3 O Proformação: curso a distância, de formação para o Magistério, em Nível Médio (modalidade Normal) para quem não possuíam habilitação mínima legalmente exigida e já lecionam nas quatro primeiras séries, classes de alfabetização e de jovens e adultos das redes públicas estaduais e municipais de todo o país. (PROFORMAÇÃO/ maio de 2004, p.4)

4 LDBEN/96 - BRASIL, 2006, v 2., il - "no mínimo diploma de nível médio modalidade Normal e, preferencialmente, de nível superior (pedagogia)" .

5 Edital conjunto SME/SMA nº 08 de 24/07/2007.

Criar Educação, Criciúma, v. 6, n², julho/novembro 2017.- PPGE - UNESC 
emergencial, operacionalizado, nessa cidade pela Universidade Federal do Rio de Janeiro, governo estadual e municipal, com os seguintes propósitos: (i) habilitar para o magistério os recém-concursados $A A C$, que exerciam atividades docentes na Educação Infantil sem formação; (ii) propiciar conhecimentos que levassem ao aprimoramento das práticas pedagógicas dos profissionais em exercício docente; (iii) melhorar a formação dos participantes, oferecendo crescimento profissional e pessoal; e, primordialmente, (iv) contribuir para uma Educação Infantil de qualidade compromissada com a criança (BRASIL, 2005).

Este artigo apresenta a política pública - PROINFANTIL - pelo viés da abordagem do ciclo de políticas. Esta abordagem constitui-se num referencial teórico-analítico propício à análise de programas e políticas educacionais. Envolve estratégias de elaboração e de desenvolvimento utilizadas por pessoas nos diferentes momentos de apropriação de uma política. Considera as tensões, os embates e os compromissos produzidos durante a execução. Para tal, busca compreender a produção e negociação de sentidos e significados que compõe os diferentes contextos da política analisada. Neste trabalho, o processo político é entendido como um ciclo multifacetado e dialético, por isso para interpretá-lo foi necessário articular o discurso dos diferentes sujeitos envolvidos. Entender este novo olhar para as políticas requer, de acordo com LOPES (2006) e LOPES \& MACEDO (2006), um estudo diferenciado dos sujeitos, tanto na sua historicidade quanto nos seus discursos.

A estrutura, as concepções e a metodologia do PROINFANTIL foram analisadas, objetivando investigar as transformações ocorridas na prática das cursistas, decorrentes do programa de formação e representados no trabalho final de curso.

\section{METODOLOGIA}

Ball (1994) argumenta que a política é, ao mesmo tempo, texto e ação. Os interesses envolvidos apresentam forças muitas vezes ocultas e invisíveis. Por isso, as políticas não são implementadas e recebidas, elas tomam força à 
medida que todos os participantes envolvidos compreendem os textos e dão a eles novos significados, resultantes de suas recriações nos diversos contextos em que atuam. De acordo com autor (1994, p. 22) "Nós falamos através das políticas, nós ocupamos as posições construídas por nós, dentro das políticas." A partir desta visão o caminho metodológico percorrido no contexto de influência do PROINFANTIL, foi de análise dos aspectos de surgimento das políticas, tanto local como global e dos discursos construídos sobre eles.. Tais discursos repercutem nas esferas nacionais e locais, recebem influências diversas, inclusive de organismos internacionais ${ }^{6}$, que operam ora como consultores ora como financiadores das reformas educativas. Num segundo momento, elementos do contexto da produção do texto foram analisados: o início do processo da escrita desse programa, os autores e seus discursos, além das vozes que ressoaram na elaboração do mesmo. Do contexto da prática: as concepções de criança produzidas pelos AAC nos Projetos de Estudos $^{7}$ constituíram-se no foco das analises.

\section{RESULTADOS E DISCUSSÃO}

\subsection{O PROINFANTIL e as tensões das demandas legais: contexto de influência}

O contexto de influência do PROINFANTIL - apresentou as tensões das demandas legais, as disputas sobre as finalidades e os meios utilizados para a construção do programa, sob a ótica da legislação vigente à época da sua confecção. Os elementos de articulação da política nos diferentes níveis: global, nacional, estadual, municipal e social foram analisados. A formação dos profissionais da Educação Infantil (legislação) e as influências de ordem global

6 Os organismos internacionais serão apresentados mais oportunamente.

7Trabalho de conclusão de curso- descrição das atividades desenvolvidas pelo cursista a partir do eixo temático definido pela UFRJ e EEG : "Infância, cultura e cidadania em instituições de Educação Infantil em municípios do Estado do Rio de Janeiro". Objetivo "desenvolvimento da competência de interpretar a realidade, refletindo sobre a própria prática e produzir novos significados para transformá-la".

Criar Educação, Criciúma, v. 6, n², julho/novembro 2017.- PPGE - UNESC 
no Brasil (organismos internacionais e as políticas educacionais) foram traduzidas nas interrelações dos diferentes níveis (CAMPOS, 2014).

O contexto da influência é o espaço no qual a política pública se inicia e os discursos são pensados e construídos. Sendo assim, o PROINFANTIL é resultado de um processo histórico, cultural e dialógico de seu tempo. As produções das cursistas foram compreendidas como produto de múltiplas vozes, resultantes dos encontros que sempre envolviam negociações, disputas, acordos, tensões e intenções nos mais variados níveis.

Embora o contexto de influência tenha uma ligação intrínseca com os outros contextos (produção de texto e prática) neste artigo, o PROINFANTIL é tratado sob a ótica da legislação vigente à época da sua confecção e sua significação como curso de formação de professores de Educação Infantil. Fazse necessário analisar as interrelações dos diferentes níveis e processos políticos (macro, intermediário e micro) e suas contínuas relações.

A análise das políticas por ciclos traduz uma valorização de outras dimensões do processo político, através da ênfase na complexidade das relações, dos discursos e das práticas que constituem as políticas, além das interpretações e reinterpretações dos sujeitos (LOPES e MACEDO, 2006). Para compreender o programa foi necessário voltar ao Plano Nacional de Educação (2001- 2011) , um desdobramento do compromisso assumido pelo Brasil nos acordos internacionais referente à expansão e aprimoramento da educação da primeira infância, especialmente para as crianças mais vulneráveis e desfavorecidas. Alguns desses acordos internacionais: Banco Mundial (1995, 1999, 2002), Programa de Promoção das Reformas Educativas na América Latina (PREAL, 2004) enfatizavam a necessidade de expansão e aprimoramento da educação na primeira infância. Na mesma época foram produzidos outros documentos: Declaração mundial sobre a educação superior no século XXI: visão e texto marco referencial de ação prioritária para a

8 Plano Nacional da Educação - PNE 2001-2011, aprovado pela Lei n ${ }^{\circ}$ 10.172, de janeiro de 2001, estabeleceu metas de ampliar a oferta de atendimento em pré-escolas- 4 a 6 anos - para 60 por cento da faixa etária correspondente, no prazo de cinco anos, e de 80 por cento, ao fim da década. Para a creche - 0 a 3 anos - foram fixados os percentuais de 30 a 50 por cento, respectivamente, para os mesmos períodos.

Criar Educação, Criciúma, v. 6, n², julho/novembro 2017.- PPGE - UNESC 
mudança e o desenvolvimento do ensino superior (UNESCO, 1998); Declaração de princípios da Cúpula das Américas (2001); e Fórum Mundial de Educação (Dacar, 2000). Em todos esses documentos havia a presença nítida da ideia de preparar professores para a nova economia mundial (GATTI, 2008) Dentre os setoriais de educação elaborados pelo Banco Mundial, está o relatório produzido pela organização em 2001 e traduzido no Brasil em 2002, intitulado "Desenvolvimento da Primeira Infância: foco sobre o Impacto das PréEscolas". Essa proposta apontava para a melhoria na qualidade do ensinoaprendizagem, por meio de programas direcionados ao desenvolvimento da criança, do nascimento à primeira infância, como meio de reduzir desequilíbrios e promover um crescimento econômico sustentável.

Com a promulgação da Lei n. 9.394 (BRASIL, 1996), chega-se ao final da década de 1990, sob a pressão de um novo patamar: vincular todas as instituições de Educação Infantil, inclusive as crianças de 0 a 3 anos, ao sistema municipal de ensino. É possível afirmar que, no período (2003-2011) houve avanços na educação em geral e continuidade em muitas ações iniciadas nos governos anteriores.

\subsection{O PROINFANTIL como programa de formação: contexto da produção de texto}

O contexto de produção de política é qualificado por Ball (1994) como o campo da elaboração de ideias, textos, documentos e propostas oficiais, enquanto representações codificadas e decodificadas sujeitas a influências de várias instâncias. De acordo com o mesmo autor (1992), tanto o texto da política, quanto os respectivos autores e leitores têm histórias que interferem nas representações.

O programa de formação foi analisado a partir dos elementos do contexto da produção do texto, da proposta do curso em questão, sua incorporação e intervenções textuais, além das limitações materiais e possibilidades vivenciadas no contexto da prática. Para BALL \& MAINARDES (2011), o poder do texto como política aparece na historicidade dos sujeitos 
que ali estão. No caso do PROINFANTIL, foram os profissionais que elaboraram e que usufruíram da política pública nos três âmbitos (federal, estadual e municipal) e suas interpretações como "sujeitos históricos que recebem e interpretam os textos de diferentes formas" (MAINARDES, 2007, p. 37). Nessa perspectiva, os leitores (principalmente os cursistas) foram considerados e analisados não como meros receptores, mas sujeitos críticos e competentes produtores de diferentes interpretações da realidade proposta.

Para este artigo, a observação de alguns fragmentos do discurso e do texto da política estudada forneceu elementos para uma análise crítica. Houve, ainda, o aprofundamento da relação com os saberes e experiências da formação dos docentes cursistas, sobre a própria prática o que possibilitou a compreensão das transformações produzidas a partir dos referenciais teóricos e dos encontros reflexivos.

Os textos disponibilizados pelo PROINFANTIL como material didáticopedagógico para as AAC tiveram a pretensão de ser, segundo os dizeres de Ball (1992), ao mesmo tempo, readerly e writerly ${ }^{9}$. Foram textosreaderly ${ }^{10}$ porque algumas vezes encontraram leitores acríticos que o interpretaram ao pé da letra, sem levar em consideração o contexto em que eles próprios os elaboravam. Por outro lado, foram textos writerly ${ }^{11}$ à medida que foram produzidos a partir da história de docência e das conquistas de cada um dos Agentes Auxiliares de Creche, que participou da formação e produziu significados diferenciados em suas práticas.

O que parece ter diferenciado os estilos de textos foi no contexto da prática: a própria história do AAC, a maneira como a formação elaborada pelo programa foi apresentada, o momento de reflexão em cima de suas práticas e a própria política municipal na qual estavam inseridos. De acordo com Lopes

9 Para analisar melhor essa concepção, Ball e Bowe (1992) com base nos trabalhos de BARTHES (1992), distinguem dois tipos de textos:writerly (escrevivel)e readerly (prescritivo).

10 Texto readerly-o leitor é um receptor passivo, limitado na produção de sentidos, assume a condição de não-crítico.

11Texto writerly convida o leitor a ser crítico, e co-autor da produção

Criar Educação, Criciúma, v. 6, n², julho/novembro 2017.- PPGE - UNESC 
(2006), os efeitos das políticas como textos e como discursos são contextuais e estabelecem constrangimentos, à medida que são múltiplos. Foi possível perceber esta realidade a partir dos produtores de textos e discursos (Projetos de Estudo).

Dessa forma, destacamos que política como texto e política como discurso são conceituações que se complementam e compõem processos complexos, visto que não se limitam a uma representação estática, pois envolvem poder, interesses e histórias diversas. O contexto da produção do texto e da política PROINFANTIL foi constituído em uma série de documentos, legislações, pronunciamentos que envolviam as ideias, as soluções encontradas em livros, periódicos, conferências que acabaram por serem traduzidas na concepção do programa. O resultado foi a produção de um currículo com intenção de proposta pedagógica, em eixos tanto verticais, quanto transversais de concepções: (i) de educação (processo permanente enfocando o caráter histórico e social do conhecimento), (ii) de aprendizagem (desenvolvimento das competências adquiridas no processo de formação pessoal e profissional por meio de (re)significações, (iii) de instituição de educação infantil (espaço de cuidado e educação, organizado e planejado para atender crianças de 0 a 5 anos de idade), (iv) de criança (cidadão de direitos e um sujeito sócio-históricocultural), (v) de conhecimento escolar (resultado da construção que se processa a partir da interação com diferentes tipos de conhecimento), (vi) de prática pedagógica (a prática social, ou seja, a reflexão do seu trabalho pedagógico à luz da teoria), (vii) de avaliação (parte inerente do processo de ensino e aprendizagem), (viii) de interdisciplinaridade (abordagem de vários olhares para um determinado conhecimento) e (ix) construção da identidade profissional (eixo vertical e transversal do programa). (BRASIL, 2005).

\subsection{O PROINFANTIL e o contexto da prática}

O contexto da prática, neste artigo, destaca o curso de formação e merece especial atenção, pois é para ele que as políticas são endereçadas. É nele que são (re)significadas as concepções apresentadas nos documentos 
oficiais e são produzidos os efeitos positivos e negativos das políticas, no fazer cotidiano das cursistas. Foram 44 (quarenta e quatro) os Projetos de Estudos tarefa de conclusão do curso - tomados como objeto de análise.

Neles os sentidos atribuídos aos textos políticos têm consequências reais, pois ajudam os participantes a rever suas concepções e a pensar sobre elas, levando a interpretações e recriações de suas próprias ações pedagógicas, podendo, até mesmo introduzir mudanças e transformações relevantes, não só aos seus próprios fazeres cotidianos como à política original.

A análise dos Projetos de Estudos permitiu perceber a relação estabelecida entre a formação das AAC no PROINFANTIL e suas visões de criança. Essa relação possivelmente indicou as concepções de criança que estavam subjacentes ao fazer pedagógico, na educação infantil, desses profissionais. Ao analisar a concepção de criança nos Projetos de Estudos ficou evidente que o sentido empregado pelas AAC às concepções foi um processo de construção interna e que os significados compartilhados no curso apareceram como resultado das vivências ocorridas na formação, associado ao repertório profissional, singular e cotidiano de cada cursista.

Os Projetos de Estudos revelavam as interpretações ou versões da realidade prática das $\mathrm{AAC}$, de acordo com a leitura compreensiva que cada uma fez dos textos, em paralelo às suas posições, condições, visões políticas, credos; além do momento histórico-cultural vivido. Este produto final de curso se contextualizou dentro de uma conjuntura maior: por um lado, o próprio curso de formação - PROINFANTIL - com seu material didático e suas aulas; por outro, o fazer cotidiano na creche na qual a AAC trabalhava, o suporte institucional às suas práticas e, por último, a Secretaria Municipal de Educação à qual as creches e as próprias AAC estavam vinculadas.

\section{CONCLUSÃO}

Os resultados apontaram que o PROINFANTIL, enquanto política foi reinterpretada e recriada por cada cursistas de forma singular. Os discursos e 
textos foram transformados, ignorados, rejeitados, mal entendidos ou até mesmo burlados, pois "interpretação é uma questão de disputa" (BOWE apud MAINARDES, 2007, p.30), uma vez que cada interpretação se relacionou com interesse próprio de cada participante. Como foram diversos os interesses em jogo, sempre havia a possibilidade de diferentes interpretações. Ficando claro que a atribuição de diferentes sentidos foi essencial na manutenção de um processo dialógico, que garantia a sobrevivência da própria política.

Procuramos entender as (re)significações dos conceitos de criança tão relevantes para a atuação profissional, após a participação no curso de formação. Isto implicou em resgatar, de cada uma a própria trajetória, enquanto cursista de uma formação continuada, trazendo a objetividade da profissão e a subjetividade de cada um. Neste contexto, identificamos a confluência de conteúdos tanto da esfera privada/pessoal quanto daquelas que se constituem no coletivo do trabalho das creches e nas políticas municipais.

\section{REFERÊNCIAS}

BALL, Stephen; BOWE, Richard; GOLD, Anne. Reforming Education \& Changing Schools: case studies in Policy Sociology. New York: Routledge, 1992.

BALL, Stephen J.; BOWE, Richard. Subject departments and the "implementation" of National Curriculum policy: an overview of the issues. Journal of Curriculum Studies, v. 24, n. 2, p. 97-115, 1992.

BALL, Stephen J. Education reform: a critical and post-structural approach. Buckinghan: Open University Press, 1994.

. Diretrizes políticas globais e ralações políticas locais em educação.

Currículo sem fronteiras, v.1, n.2,p. 27-43, 2001. 
. Reformar escolas/reformar professores e os terrores da performatividade. Revista Portuguesa de Educação, Braga, v.15, n.2, p. 3-23, 2002. Disponível em: <www.redalyc.org>.

- Stephen Ball e a educação (entrevista a Lucíola Licínio de C. P.Santos). Educação em Revista, Belo Horizonte, n.40, p.11-25, dez. 2004.

BALL, Stephen J. Sociologia das políticas educacionais e pesquisa críticosocial: uma revisão pessoal das políticas educacionais e da pesquisa em política educacional. Currículo sem Fronteiras, v.6, n.2, p.10-32, jul./dez. 2006.

BALL, Stephen J.; MAINARDES, Jefferson (orgs). Políticas educacionais: questões e dilemas. São Paulo: Cortez, 2011.

BARTHES, Roland. S/Z. Rio de Janeiro: Nova Fronteira. 1992

BRASIL. (Constituição de 1988). Constituição da República Federativa do Brasil. Brasília: Senado Federal, 1988.

BRASIL. Lei $n^{\circ}$ 9.394, de 20 de dezembro de 1996. Estabelece as diretrizes e bases da educação nacional. Legislação. Brasília: Casa Civil da Presidência da República, 1996a. Disponível em: <http://www.planalto.gov.br/ccivil_03/Leis/L9394.htm>.

BRASIL. PROINFANTIL: Programa de Formação Inicial para Professores em Exercício na Educação Infantil: Guia Geral- Brasília: Ministério da Educação, Secretaria de Educação Básica, 2005. 51 p. (Coleção Proinfantil)

CAMPOS, Maria Ignez F. O PROINFANTIL no município do Rio de Janeiro: concepções de criança nos Projetos de Estudos. Dissertação de Mestrado em Programa de Pós-Graduação em Educação - PROPED/UERJ, 2014. 
GATTI, Bernardete. Análise das políticas públicas para formação continuada no Brasil, na última década. Revista Brasileira de Educação, v. 13, n. 37, jan./abr. 2008.

LOPES, Alice C.. Discursos nas políticas de currículo.Currículo sem Fronteiras, v.6, n.2, p. 33-52, jul./dez. 2006.

LOPES, Alice C.; MACEDO, Elizabeth. Nota Introdutória: reconfigurações nos estudos sobre políticas de currículo. Currículo sem Fronteiras, v.6, n.2, p.5-9, jul./dez. 2006

MAINARDES, Jefferson. Abordagem do ciclo de políticas: uma contribuição para análise de políticas educacionais. Revista Educação e Sociedade, Campinas, vol27, n.94, p.47-69, jan/abr.2006. Disponível em <http://www.cedes.unicamp.br>.

. Reinterpretando os ciclos de aprendizagem. São Paulo: Cortez, 2007. 